\title{
Leszek Kolakowski: La importancia de seguir pensando lo irresoluble
}

\section{Leszek Kolakowski: The importance of keep on thinking the irresoluble}

\author{
CARlos Gómez \\ UNED, Madrid
}

In memoriam

RESUmen. Tras la presentación y un esbozo biográfico, se consideran algunos ejes de la obra de Kolakowski: la crítica del marxismo, el interés por la religión y el cuestionamiento metafísico. El profundo conocimiento de los clásicos y de las principales tendencias de la filosofía contemporánea, así como el seguimiento de los debates nuestro tiempo, hacen de Kolakowski un pensador cosmopolita, a pesar de la independencia de su pensamiento, nutrido de tensiones que es preciso saber mantener en vez de decantarse unilateralmente por uno de los polos de las mismas. Aunque no podamos esperar un orden social y un sistema filosófico que logren resolver nuestros interrogantes, el pensamiento que los considera, en vez de procurar cancelarlos, tiene la ventaja de mostrarnos por qué, pese a que no podamos resolverlos de manera cabal, es importante que nos los sigamos planteando.

Palabras clave: Crítica del marxismo, política, religión, ética, metafísica, tensiones filosóficas, interrogantes irresolubles.

El 17 de julio de 2009 murió Leszek Kolakowski, sin duda uno de los pensadores más notables de nuestro tiempo. Crítico
Abstract. After the presentation and the biographical outline, a few core aspects of Kolakowski's work are taken into consideration: the criticism of Marxism, the interest in religion and the metaphysical questioning. His connoisseurship of classical sources and of the leading trends in present-day philosophy, together with his follow-up of the controversies of our time, account for Kolakowski's philosophical cosmopolitanism, notwithstanding the independence of his thinking, nourished by tensions whose upholding - rather than the unilateral positioning by one stance or the other- is of the essence. Even when a social order and a system of thought cannot be called upon to solve our questions, the thinking that takes them into account, instead of endeavouring in waiving them, has the advantage of showing us why, even if we cannot unravel them painstakingly, it is important for us to keep posing them.

Key words: Criticism of Marxism, politics, religion, ethics, metaphysics, philosophical tensions, unsolvable questions.

implacable del marxismo, tras haber pasado por él y haber militado en el Partido Comunista polaco, exiliado desde 1968 
en Inglaterra, no por ello se dejó acunar en los brazos del liberalismo capitalista sin las oportunas distancias, hasta el punto de llegar a definirse en algún momento como un conservador-liberal-socialista, fórmula que pone bien de manifiesto la dificultad de encasillar su pensamiento. Con una sólida formación en la filosofía antigua y la escolástica medieval, estudioso del pensamiento moderno (su tesis doctoral fue sobre Spinoza), simpatizante de Kant, o al menos de sus preguntas filosóficas, sin por ello verse forzado a considerarse ni kantiano ni kantólogo, conoció asimismo todas las grandes corrientes filosóficas de nuestro tiempo, no sólo el marxismo por tanto, sino también la filosofía analítica y los movimientos derivados de la fenomenología, como el existencialismo y la hermenéutica, a todo lo cual se añadía un profundo interés por la religión y el pensamiento teológico, el oficial y el de las diversas sectas y tendencias que el cristianismo ha conocido a lo largo de su existencia. Conservador crítico de nuestra cultura, liberal que denostaba el «individualismo posesivo»y seguía preocupado por la justicia social, socialista sin partido, cristiano sin iglesia, su pensamiento tendía a deshacer los tópicos consagrados, las modas intelectuales, los dogmas establecidos, las muletillas consideradas irrecusables, tratando de forzarnos con su crítica a lo que él ejerció de manera ejemplar, pensar informadamente pero por cuenta propia. También, a saber mantener las tensiones que vivifican un pensamiento y una actitud, sin el consuelo de una pretendida solución definitiva a nuestros interrogantes, pero sin arrellanarse por ello en el butacón de la desesperanza conformista, suavemente escéptica, fácilmente relativista, acomodada al orden vigente de turno. A través de numerosos estudios y enfoques, no dejó de insistir de un modo u otro en que, aunque no podemos esperar un or- den social y un sistema de pensamiento que logren aplacar nuestras inquietudes y nuestras preguntas, el pensamiento que las considera en vez de procurar cancelarlas, tiene al menos la virtud de ser capaz de acoger nuestra condición y de mostrarnos por qué, pese a que no podamos resolverlas de manera cabal, es importante que nos las sigamos planteando, que no las sofoquemos, que sepamos aún mantenerlas en pie.

Nacido en 1927 en Radom, Polonia, durante la Segunda Guerra Mundial su padre, un economista y escritor político, fue asesinado por la Gestapo y Kolakowski se vio forzado a seguir una formación en buena medida autodidacta, eventualmente apoyada por maestros de la resistencia polaca. (Más tarde contó alguna vez que como en su casa encontró una enciclopedia, pero estaba incompleta, conocía todo lo que empezaba por A, $\mathrm{D}$ y E, pero en cambio ignoraba todo a propósito de lo que comenzase con $\mathrm{B}$ o C). Quizá esos factores biográficos, unidos a otras circunstancias, así como al deseo de alejarse del conservadurismo clerical de su país, ayuden a explicar su afiliación, tras la guerra, a las organizaciones juveniles y al Partido Comunista, mientras estudiaba Filosofía en la Universidad de Lodz, donde fue ayudante durante algún tiempo. Doctor en 1953 por la Universidad de Varsovia, en ella trabajaría, primero como ayudante y más tarde como Profesor Titular de Filosofía Moderna, a la vez que colaboraba en diversas revistas y era miembro del consejo editorial de Nowa Kultura. Aunque no sería expulsado de su puesto hasta 1968 , su disidencia venía de tiempo atrás y puede remontarse al menos a 1950, cuando, enviado por el Partido a Moscú para seguir unos cursos de formación dirigidos a prometedores intelectuales comunistas, los encargados de impartirlo le causaron una impresión deplorable, abriéndole dicha visita los ojos a lo que más tarde 
describiría como «la enorme desolación material y espiritual provocada por el sistema estalinista». Kolakowski se convertirá a partir de entonces en una de las principales figuras del revisionismo marxista polaco, tratando de impulsar la democratización del país. Esas demandas parecía que iban a poder tomar cuerpo con la muerte de Stalin en 1953 y, en particular, con los disturbios y muertes de los trabajadores en Poznan, el «octubre polaco» de 1956, que llevaron al reformista Wladyslaw Gomulka al poder y a proclamar la independencia provisional respecto a Moscú. A esa etapa pertenece Qué es el socialismo, un ensayo que circuló clandestinamente durante meses, y en el que Kolakowski ofrece un conjunto de definiciones irónicas de lo que no es, pero que en realidad lo retratan (el socialismo no es una sociedad cuyos dirigentes se nombran a sí mismos en sus puestos, en la que un hombre contraiga problemas por decir lo que piensa, en la que viva mejor quien no tenga pensamientos propios; el socialismo no es un estado que tenga más espías que enfermeras y más gente en prisión que en el hospital, etc.), satirizando los males del estalinismo, pero enseguida también, desaparecido el señuelo reformista, el Estado polaco, que cada vez más vigilará sus actividades. Finalmente, en 1966, a raíz de una conferencia que pronunció en el aniversario de los acontecimientos de una década antes, fue expulsado del Partido Comunista y dos años más tarde de su cátedra, por «conformar las opiniones de la juventud de modo contrario al pensamiento oficial del país». Acompañado de su esposa Tamara, judía y psiquiatra de profesión (con la que se había casado en 1949 y con quien tendría una hija), abandonó el país, mientras sus escritos eran prohibidos, lo que no logró impedir la circulación de ediciones clandestinas ni su influencia en intelectuales polacos disidentes y en las actividades del Comité para la Defensa de los Trabajadores (KOR), del que él fue miembro en el extranjero, así como su posterior colaboración -intelectual, política y económica, recaudando fondos - con el movimiento Solidaridad de Lech Walesa.

Mientras tanto, Kolakowski se había exiliado en América del Norte, como profesor invitado en la Universidad McGill de Montreal, más tarde en la Universidad de California, Berkeley, para, a partir de 1970, trasladarse a Gran Bretaña, donde se convirtió en investigador en All Souls College, un college sin estudiantes, en Oxford, aunque periódicamente impartía lecciones de Filosofía en la Universidad de Chicago, además de ser miembro del Committee on Social Thought de dicha Universidad. Aunque relativamente poco conocido en Gran Bretaña, fue sin embargo miembro de diversas Academias, y acabó por recibir numerosos reconocimientos a su labor, como el Premio de la Paz de la Asociación de Libreros Alemanes (1977), el Premio Erasmus (1983), el Premio Jefferson (1986), el Premio Pen Club de Polonia (1988), el Premio Kluge de la Biblioteca del Congreso de Estados Unidos en su primera edición (2004), por la labor realizada en el campo de las humanidades, o el Premio Jerusalem (2007), por su aportación a «la lucha por la libertad del individuo en la sociedad».

El estudio de las diversas corrientes del pensamiento contemporáneo se manifiesta en obras como La filosofía positivista, de Hume al Círculo de Viena (1966) o Husserl y la búsqueda de la certeza (1975), pero durante un tiempo continuó siendo el marxismo uno de sus principales objetos de preocupación, primero desde una perspectiva revisionista, tal como se manifiesta en Hacia un humanismo marxista (1967), donde rechaza el determinismo económico y subraya la responsabilidad moral del individuo, luego alejándose definitivamente de dicho 
paradigma, como revela la que para muchos es su opus magnum, las Corrientes fundamentales del marxismo, publicada por primera vez en París, en polaco, por el Polish Literary Institute, entre 1976 y 1978, más tarde en Londres, en inglés, en 1978 (la edición española, en Alianza Universidad y con traducción de Jorge Vigil, aparecería poco después, entre 1980 y 1983). Sus tres volúmenes (Los precursores, La edad de oro, La crisis), de una inmensa erudición, se han convertido, se compartan o no sus puntos de vista y su línea interpretativa, en obra de referencia indiscutible para el estudio del marxismo, particularmente en su aspecto teórico. El tercer tomo, en el que aborda el pensamiento marxista más reciente, también el elaborado en Europa Occidental, resultó particularmente hiriente para muchos de sus defensores por la aguda crítica con que Kolakowski trataba de desmontar vigencias y modas intelectuales, consideradas intocables por la izquierda. Entre otras cosas, denostó (quizá en exceso, aunque no le faltaran buenas razones, ni desde luego conocimiento) la pedantería y pretenciosidad del marxismo alemán de Bloch a los frankfurtianos, el marxismo campesino de Mao, que tanto furor estaba desatando entre algunas cabezas pensantes europeas, o los neologismos inútiles y hueros de la Crítica de la razón dialéctica de Jean-Paul Sartre (¿se deberá a ello y a la tendencia de los franceses a proclamar a sus pensadores, a poco que te descuides, monumento nacional, el hecho de que aún no se pueda disponer de ese volumen en francés?). Los apologistas occidentales del marxismo trataban de justificar la falta de libertad política de los regímenes del Este, basándose en su progreso económico y en la transitoriedad de aquel cercenamiento, mientras se construía la nueva sociedad. Pero los dos supuestos eran falsos. La propiedad estatal de los medios de producción, medicina universal de los mar- xistas para todos los males sociales, no sólo es compatible con todos los desastres del capitalismo - explotación de inmensas masas sociales, despilfarro económico, contaminación ambiental, odios nacionales, imperialismo...-, sino que añade otros de cosecha propia: ineficiencia, falta de incentivos, burocratización gigantesca, desigualdad básica entre los dirigentes y la mayor parte de la población $\mathrm{y}$, sobre todo, una concentración de poder -económico, político, ideológico- jamás conocido, concentración que ahoga la separación de poderes que pudiera contrarrestar el de unos grupos o instituciones frente a otros y yugula cualquier atisbo de libertad. Pensar que estas carencias son provisionales es abandonarse a un señuelo incumplible, pues la esclavitud se integra en la sociedad de los países comunistas como condición absoluta de vida. Si muchos de esos puntos de vista, quizá hoy - tras el desmoronamiento de los llamados regímenes del «socialismo real»- son más generalmente asumidos, la crítica de Kolakowski tiene el valor de realizarse cuando no se solía hacer pero era más necesario ejercerla, cuando nadie podía prever el abrupto final de esos regímenes y muchos aún andaban encandilados con ellos o encontraban una indefinida capacidad de disculpa.

Pero, tal vez, lo que más pudo enojar a la izquierda occidental era la tesis de Kolakowski de que el leninismo y el estalinismo no eran simples contingencias históricas, desviaciones aberrantes de una doctrina marxista que quedaba a salvo de esos reproches. Antes al contrario, Kolakowski sostuvo y argumentó detenidamente que, aunque ese curso de los acontecimientos no era ineluctable, tampoco resultaba ajeno o una posibilidad totalmente extraña a la obra de Marx, cuyo humanismo prometeico fomentó una de las mayores y peores fantasías de la humanidad. Es cierto que las ideas del na- 
zismo le parecían aún peor —eran, si se quiere, la expresión explícita del mal en una de sus formas más abyectas. Pero el nazismo había sido derrotado y en cierto sentido las del socialismo resultaban más equívocas, al apelar a eslóganes humanistas que podían hacer sucumbir la lucidez de muchas mentes, a las que atrajo con su aparente sencillez de «explicar toda la historia y toda la economía, sin necesidad de estudiar seriamente ninguna de las dos disciplinas»». El propio Marx indicó que el comunismo en su totalidad podía resumirse en la fórmula «abolición de la propiedad privada», mas la entera centralización de los medios de producción no es separable de la más completa administración de toda la vida humana, como ya algunos críticos del marxismo advirtieron en el siglo XIX, es decir, antes del advenimiento del régimen soviético. Así pues, como insistirá en su artículo «Las raíces marxistas del estalinismo» (Estudios públicos, 11, 1983, 205-225; originalmente publicado en Robert C. Tucker, ed., Stalinism, Nueva York, Norton and Company, 1977), el leninismo y el estalinismo estaban justificados desde la lógica de la filosofía marxiana, en la que indudablemente hay elementos valiosos, pero en la que se produce una mezcolanza de descripción social, prescripción moral y predicción política, combinando una visión romántica (la de la perfecta unidad de la humanidad, entre sí y con la naturaleza, en el futuro) con la mitología del proletariado como detentador de un privilegio epistémico respecto a los objetivos últimos de la historia. A lo que se agrega una herencia teológica secularizada, que pretende, intrahistóricamente, la salvación del hombre. Todo lo cual no tiene nada de extraño que desemboque en regímenes totalitarios.

Entre las críticas que su alejamiento del marxismo desató, destaca la amplísima carta abierta, de cien páginas, escri- ta por el historiador Edward Thompson, publicada en el anuario The Socialist Register en 1973, reprochándole haber abandonado el marxismo revisionista que ambos habían defendido, para apostatar de él y abrazar el liberalismo. La respuesta de Kolakowski - aparecida en la misma publicación, al año siguiente--, de título irónico, My Correct Views on Everything (traducido como «Por qué tengo razón en todo», en el volumen del mismo título editado en Melusina, en 2007) no tiene desperdicio y en ella repasa muchos de los tópicos de la izquierda marxista europea de la época: es todavía pronto para juzgar los regímenes del «socialismo real», pues cincuenta años son pocos «a ojos de un historiador», que se puede permitir pasar negligentemente sobre el cúmulo de atrocidades practicadas, pese a esgrimir a menudo firmes criterios morales, que se trasmutan, sin embargo, en el punto de vista del filósofo de la historia o el frío racionalista cuando se trata de juzgar «la nueva sociedad alternativa»; los testimonios de los exiliados de los países del Este, de los que sufrieron las torturas y persecución de esos regímenes y lograron escapar, son inmediatamente tachados de reaccionarios, por extrapolar unos cuantos decenios de vivencias insignificantes y cuestionar el feliz futuro socialista ingeniado según los mejores modelos marxistas-leninistas por los ideólogos de la Nueva Izquierda de los países occidentales; la falta de libertad y la concentración de poderes en un mismo aparato constituyen un paréntesis necesario hacia la verdadera libertad de que gozarán los bienaventurados del paraíso socialista, frente a la meramente formal y burguesa de los países occidentales (y por eso, siempre entrecomillada en la obligada ortografía izquierdista, a la que el propio Thompson recurre), paraíso, según Thompson, «de aquí a dos centenares de años», en el que una vida idílica se 
abre ante nosotros (fuentes de energía fácilmente accesibles, posibilidad de compaginar las labores del campo con la vida intelectual, recuperación de los valores de la ciudad-estado combinados con el más amplio cosmopolitismo, etc., etc.), y ante el valor de tal ensueño, quizá no esté de más soslayar de algún modo los tropiezos de los regímenes comunistas realmente instalados, que a Kolakowski, en cambio, no le parecían un mero golpe de mala fortuna, sino algo inscrito en el proyecto mismo. Yo no sé si, como asevera Tony Judt («iAdiós a todo eso? Leszek Kolakowski y el legado marxista», en Los olvidados del siglo $X X$, trad. de Belén Urrutia, Madrid, Taurus, 2008, 133-147), nadie que lea esa polémica podrá volver a tomarse en serio a Thompson, pero sí le muestra mucho más dogmático de lo que podría suponerse, si es que no «condescendiente y mojigato», como además le juzga el propio Judt. Kolakowski, por su parte, no deja de mostrar asimismo su asombro ante los movimientos contestatarios estudiantiles que se encontró al venir a Occidente, pues, sin negar los males de las Universidades, lo que le asombra no es la ignorancia, habitual entre los jóvenes, sino el marasmo y la decadencia intelectual en que pretendían sumirlas con su arrogancia supuestamente revolucionaria frente a los cerdos fascistas del establishment (Kolakowski no se refiere a los campus universitarios españoles, sino a los de Estados Unidos o Alemania, donde las consignas se repiten con pasmosa monotonía) y propuestas tan atractivas como que se organizasen clases sobre la función social de las matemáticas, o, en Filosofía, sustituir la lectura obligatoria de Platón, Descartes, Kant y otros bobalicones burgueses, por la de filósofos verdaderamente grandes, como el Che Guevara y Mao. Pero, para no malgastar tinta ni seguir esforzándose con esa retahíla, concluye su réplica pa- rafraseando un célebre pasaje de Hamlet y pronostica ya entonces que la calavera del marxismo no volverá a sonreír. Lo cual no significa que la opción socialista esté condenada a desaparecer, pero para ello es preciso ser consciente de la complejidad de los valores puestos en juego y de su mutua limitación, que torna inviable el sueño de su conjugación armónica:

Cuando digo «socialismo», no me refiero a un estado de perfección. Más bien pienso en un movimiento que intenta satisfacer la necesidad de igualdad, libertad y productividad, un movimiento que únicamente vale la pena en la medida en que es consciente no sólo de la complejidad de los problemas que comporta cada uno de estos valores por separado, sino también de que se limitan mutuamente y, por lo tanto, no pueden ponerse en práctica sin hacer concesiones. Pensando (o fingiendo que pensamos) de otra manera, le sorbemos el seso a la gente y nos engañamos a nosotros mismos. Todos los cambios institucionales deberían tratarse como medios al servicio de estos valores, y no como objetivos en sí. Los cambios deben juzgarse calculando cuánto perderemos de un valor para poner en práctica otro. Cualquier tentativa de dar por absoluto alguno de los valores y de realizarlo cueste lo que cueste no sólo implica la destrucción de los dos restantes, sino también la autodestrucción del que nos interesa. Cabe decir que éste es un descubrimiento más viejo que la nana. Sólo un gobierno despótico es capaz de instaurar la igualdad absoluta, pero el despotismo supone la existencia de privilegios que destruyen la igualdad; de un modo semejante, la libertad absoluta significa anarquía, y la anarquía desemboca en el gobierno del más poderoso, y así es como la libertad absoluta se convierte en su contrario; la productividad como valor supremo también requeriría un poder despótico y, por encima de cierto nivel técnico, el despotismo se muestra económicamente inviable. Si repito aquí esos viejos truismos es porque los utopistas siguen haciéndoles caso omiso. Por eso no hay nada más fácil que construir utopías. Me gustaría que por lo menos en este punto nos pusiéramos de acuerdo. Si lo conseguimos, también nos entenderemos en otros, pese a este inter- 
cambio de observaciones cáusticas que - así lo creo- los dos sabremos perdonarnos generosamente. Esta concordia será mucho menos probable si sigues convencido de que, en principio, el comunismo es una brillante idea, aunque algo estropeada por culpa de sus menos brillantes realizaciones. Espero haberte dejado claro por qué llevo años sin esperar nada positivo de los esfuerzos por remendar, renovar, depurar y corregir la idea comunista. ¡Ay! ¡Pobre idea! Esta calavera, querido Edward, ya nunca va a sonreír.

Pero, como decíamos, su afilada crítica del marxismo, no supuso que hubiera de entregarse sin más al liberalismo capitalista ni, cuando el bloque soviético cayó, a la fantasía, de signo contrario, según la cual habíamos abocado al «final de la historia», como expresamente sentenció Francis Fukuyama - un hegeliano de derechas, de segundo o tercer ordeny muchos otros deseaban creer, con la resolución de todas las disputas fundamentales a favor del «orden» occidental, en el que Kolakowski, aunque sólo fuera por su pasado marxista y por su fuerte espiritualidad alimentada en el cristianismo, no podía dejar de percibir graves problemas, por lo que, de algún modo, sería preciso regular las injusticias generadas por el mercado. Sin entrar ahora en otros aspectos, la cuestión de la justicia social, por difusa que conceptualmente resulte, por difícil que sea llevarla a la práctica, y aun cuando los teóricos del neoliberalismo económico, «Hayek y sus adeptos», la desprecien, sigue siendo, para él, fundamental, aun cuando ya hemos dicho que, a su entender, el sueño de una perfecta conjugación de los valores en conflicto suele acabar por engendrar monstruos (El mito de la autoidentidad humana, Valencia, Teorema, 1976). Y ello en todos los órdenes, sea el político, el religioso o el más estrictamente filosófico.

Por decir ahora algo de estos últimos, Tony Judt ha insistido en lo caricaturesco de considerar a Kolakowski simplemente como «un filósofo polaco», cuando él fraguó su formación intelectual precisamente frente a algunos de los rasgos más destacados de la cultura polaca tradicional, como el chovinismo, el antisemitismo o el clericlaismo. Por lo que a la religión se refiere, es cierto que Kolakowski ha recuperado cada vez con más insistencia sus raíces cristianas, quizá las más vigorosas de la cultura occidental, aun cuando tal insistencia no reniega de la crítica al clericalismo, según se manifiesta aún en 1996, cuando advierte a sus compatriotas polacos del error de aspirar a regular la Constitución desde los supuestos «valores cristianos» («Un sermón de aficionado sobre los valores cristianos»)). Pero un buen testimonio de esa línea de pensamiento se encuentra ya en su temprano ensayo, de 1959, El sacerdote y el bufón (incluido en El hombre sin alternativa, Madrid, Alianza, 1970), donde expone algunas ideas que le acompañarán durante mucho tiempo, como la presencia de problemas teológicos, más allá de su contexto estricto, en la filosofía, la política o incluso la ciencia actuales. También en las actitudes. Una de las más pertinaces a través de todas las oscilaciones de nuestra evolución espiritual es el intento de encontrar una explicación unitaria, monista, que funcione como piedra filosofal capaz de volver la realidad por completo transparente e inteligible. Los filósofos que a ello aspiran y lo administran, congelando sus supuestos absolutos, ofician de sacerdotes, perpetuadores de las tradiciones y responsables de la continuidad cultural. Pero también hay filósofos que ponen en duda, cuestionan y se mofan de los absolutos reconocidos, oficiando entonces de bufones que remueven los sistemas de creencias tradicionales y propician el cambio cultural. Aunque Kolakowski no hace de su bufón una defensa a ultranza que lo absolutizaría, convirtiéndolo en un nuevo 
sacerdote, su preferencia se dirige hacia la filosofía del bufón, con desconfianza ante todo absoluto. Y, aunque «en la corte del rey hay más sacerdotes que bufones, de igual manera que existen en su reino más policías que artistas» y «parece que la cosa no puede ser de otro modo», su decisión, concluye entonces, «es la decisión a favor de una visión del mundo que nos abra unas perspectivas para hacer coincidir trabajosamente, en nuestro actuar entre los hombres, los elementos más difícilmente conciliables: bondad sin indulgencia universal, coraje sin fanatismo, inteligencia sin desesperación y esperanza sin ceguera».

Entre otras obras, ese interés por la religión se expresa en el monumental estudio que dio a la luz en 1965, pero en el que estuvo trabajando desde 1958, Cristianos sin iglesia: la conciencia religiosa y el vínculo confesional en el siglo XVII (Madrid, Taurus, 1983), en el que son consideradas muchas figuras usualmente desconocidas de la primera modernidad, cristianas en su inspiración, más sin vínculo eclesiástico, aunque también otras, como San Juan de la Cruz o Angelus Silesius, quizá en sus márgenes. Como en el margen se situaron Pascal y los jansenistas, sobre los que tiempo después (1995) Kolakowski escribió su Dios no nos debe nada: un breve comentario sobre la religión de Pascal y el espíritu del jansenismo (Barcelona, Herder, 1996). Pero quizá su obra más incisiva al respecto sea Religion: If There Is No God, de 1982 (Si Dios no existe. Madrid, Tecnos, 1985), en la que, además de destacar la importancia de los lazos, si no eclesiásticos, sí eclesiales para la fe religiosa (que, por individual que sea, siempre es comunitaria), Kolakowski realiza un magistral recorrido por los principales problemas de la filosofía de la religión - las relaciones entre fe y razón, el problema del mal, la mística, los vínculos entre ética y religión-, tratando, básicamente, de revalidar la tesis de Iván en Los hermanos Karamazov de Dostoievski, según la cual «Si Dios no existe, todo está permitido». Desde luego, Kolakowski no pretende mantener que desde una visión atea la distinción entre el bien y el mal se desvanezca. Como declaró explícitamente en la entrevista realizada por Humberto Beck (Letras libres, marzo de 2009), el famoso dictum de Dostoievski

No es creíble si sugiere que sin Dios la distinción entre el bien y el mal es inválida. La gente completamente secular mantiene esta distinción en mente. Los adherentes a la filosofía empirista argumentan que esta distinción es sólo la expresión de emociones y que las frases que dicen que algo es bueno o no en un sentido moral son inverificables y por tanto carecen de sentido. Yo rechazo esta doctrina. El empirismo mismo no es un postulado empírico sino una decisión arbitraria de los filósofos.

Pero adonde Kolakowski quiere conducir la cuestión es no sólo al hecho de que las creencias morales se han insertado milenariamente en el seno de las tradiciones religiosas, sino asimismo a resaltar la vinculación entre la ética y la religión, puesto que las creencias morales se adquieren de forma distinta a como lo hacen las creencias empíricas. No asentimos a esas creencias admitiendo «eso es verdad», sino sintiéndonos culpables si dejamos de acatarlas. De esta forma, la culpa, en consonancia con lo que dicen la Biblia y Sigmund Freud — que en El malestar en la cultura hizo del sentimiento de culpabilidad el principal problema de toda la evolución cultural-, sería la principal responsable de la especie humana tal como la conocemos. Ahora bien, la culpa es la ansiedad que sigue a la transgresión, no de una ley, sino de un tabú, y el tabú reside en el reino de lo sagrado (de nuevo aquí de acuerdo, al menos en este punto, con la exposición que del pro- 
blema hizo en Tótem y tabú el propio Freud, para quien, aunque la moral occidental exhibe una sofisticación que podría ocultar sus vínculos esenciales, el tabú es la forma primitiva de mandato moral y sus ecos aún resuenan en el imperativo categórico kantiano). Es cierto que nuestra cultura se esfuerza por ser una cultura sin tabúes, pero para Kolakowski esto es tanto como decir «un círculo cuadrado». Sin poder detenerme ahora más en esta cuestión de la que me he ocupado en otras ocasiones («Etica y religión», en C. Gómez y J. Muguerza, eds., La aventura de la moralidad. Paradigmas, fronteras y problemas de la ética, Madrid, Alianza, 2007, 3. ' ed. 2009; sobre el tema pueden verse asimismo: J. Muguerza, «Un colofón teológico-político», en Desde la perplejidad, México, FCE, 1990, 4. ${ }^{a}$ ed. 2006, y J. Vigil, «La filosofía de la religión de Leszek Kolakowski», en M. Fraijó, ed., Filosofía de la religión, Madrid, Trotta, 1994, 3. ${ }^{\mathrm{a}}$ ed. 2005), quizá no estuviera sin embargo de más subrayar que Kolakowski no pretende hacer valer la sentencia de Dostoievski únicamente en un sentido moral, sino también en sentido epistemológico, por cuanto, si no aceptamos como criterio definitivo de verdad el de eficiencia - algo puede ser eficiente sin ser verdad - y nos preguntamos por lo verdaderamente real, por lo realmente real, la supuesta primacía del lenguaje de las ciencias frente al religioso o el metafísico se desvanece. En realidad, tienen propósitos diferentes y su diferencia no estriba en la objetividad o en el acceso a la verdad que procuran o dejan de procurar, respectivamente, sino en que mientras el primero, en sus aspectos puramente empíricos, es apropiado para reaccionar ante nuestro entorno natural y manipularlo, el segundo trata de hacerlo inteligible, de dotarle de significado. Y, desde esa perspectiva, ¿por qué habría de ser más plausible decir, por ejemplo, que el amor místico es una derivación del Eros mundano, que decir que este último es un pálido reflejo del amor divino?

Con estas observaciones nos encaminamos a los intereses más estrictamente filosóficos $-\mathrm{O}$, si se quiere, metafísicos-de Kolakowski, tal como los ha expresado en Metaphysical Horror, de 1988 (Horror metaphysicus, Madrid, Tecnos, 1990), en donde Kolakowski, pese a las oleadas postmodernas y postmetafísicas de nuestro presente cultural, reivindica - sin desconocer las razones de esos movimientos - la importancia de las preguntas metafísicas. No por ello deja de desconfiar de las certezas supuestamente apodícticas, pero, por otra parte, rehúsa mantenerse simplemente en los criterios pragmáticos de verdad o de realidad, o en un cómodo relativismo, para acoger el deseo humano de acceder a la realidad en sí. Un deseo neurótico, si se quiere, pero entonces habría que estimar que se trata de una neurosis de raíces antropológicas tan profundas, que probablemente resulte inextirpable, de forma que las sucesivas prohibiciones filosóficas al respecto resultarán tan inútiles como las costumbres victorianas para arrumbar las cuestiones del sexo o las pilas de libros dedicados a la muerte de Dios y otros ejercicios afines para abolir la pregunta por lo divino.

Parece algo bastante incuestionable - pese a todos los pronunciamientos de empiristas, pragmatistas y escépticos acerca del triunfo inminente, final y universal de su enfoque - que la búsqueda del fundamento último es una parte tan inseparable de la cultura humana como lo es la negación de la legitimidad de esta búsqueda; y la negación, una vez articulada en idioma filosófico - y no sólo ejercida abandonando el acto de preguntar-, no es menos arbitraria que lo que niega [...]. Una vez que somos conscientes de que se producen errores e ilusiones, la cuestión acerca de la realidad que jamás puede ser ilusión, o con respecto a la verdad acerca de la cual no 
hay error posible, es ineludible, siendo vana nuestra condena de este deseo como una perversión de la pregunta - correcta y perfectamente comprensible - por la «verdad» más frugal, por una verdad que hemos de tener presente en los asuntos prácticos y que es parte de nuestra vida comunal.

Sin que hayamos de despreciar las formulaciones, siempre provisorias, que se puedan encontrar, la metafísica, como un conjunto de preguntas que acompañan al hombre si no desprecia su condición, se le muestra a Kolakowski como algo ineludible. Y de ahí quizá que su estudio de 2007, Las preguntas de los grandes filósofos (Barcelona, Arcadia, 2008), no trata tanto de ser un manual sucinto o una historia de la filosofía en forma de píldoras cuanto de que nos hagamos cargo de los interrogantes fundamentales que se encuentran a la base de las elaboraciones de los grandes pensadores, para que nos sigan dando que pensar.

En esta serie de confrontaciones y de tensiones irresolubles en las que el ser humano se encuentra, entre relativismo y absolutismo, escepticismo y dogmatismo, acomodo pragmático y aspiración a lo Absoluto, visión sagrada y visión secular; entre espíritu conservador y lucha por el cambio, entre libertad e igualdad, Kolakowski ha sabido como pocos mantener ambos extremos, sin decantarse por uno de ellos demonizando el contrario, al estimar que, por incómodo que ello pueda en ocasiones resultar, hace más justicia a nuestra fronteriza condición y exorciza los peligros letales que la unilateralización de uno de esos valores o polos suele comportar. $\mathrm{Si}$ a esto se le quiere pedantemente llamar eclecticismo, se podría aceptar la noción, siempre que con ella nos refiramos, no a una componenda que toma de cada parte o doctrina un poco, sin criterio y sin elaboración, sino a esa tarea de discernimiento, de crítica, que acompaña a lo mejor de la filosofía desde sus inicios. De crítica y de autocrí- tica, que no en vano es éste quizá uno de los valores básicos inculcados por nuestra cultura (aunque, de nuevo aquí, su absolutización tendría efectos fatales y abocaría al suicidio).

En ese continuo vaivén, en ese perpetuum mobile ¿no se atisba para el ser humano un estado mejor?, ¿no podemos aspirar a un sistema de pensamiento que resuelva básicamente nuestros problemas, a un estado social que cancele los conflictos? La aspiración forma parte de nosotros tanto quizá como la imposibilidad de solucionarlos de una vez por todas, aunque el asumir unos y otros aspectos tal vez forme parte ya del mejor camino, en el que, sin dejarnos desgarrar por esas tensiones, tal vez debamos aprender a conformarnos, frente a la morada definitiva que quisiéramos alcanzar, con albergues provisionales a modo de posada en el tiempo. De ahí el que si las utopías resultan inextirpables por cuanto arraigan en la tendencia a superar lo dado, cuando cristalizan en retablos idílicos se pervierten y trasmutan en regímenes de terror, ya sea que se basen en la aspiración a un paraíso futuro o en la exaltación sin condiciones del statu quo. Así, por ejemplo, ocurre con la idea de fraternidad, indispensable como orientación, pero espantosa cuando se trata de hacer realidad en una «fraternidad por mandato». En efecto, tal y como observó en La modernidad siempre a prueba (México, Vuelta, 1990), «la idea de fraternidad humana es desastrosa como programa político, pero indispensable como señal orientadora. La necesitamos - por volver a emplear expresiones kantianas - como idea regulativa, más que constitutiva».

Esta última alusión nos recuerda la estima de Kolakowski por Kant, en cuyos planteamientos se pueden encontrar a su entender («¿Por qué necesitamos todavía a Kant?») algunas de las mejores formulaciones para seguir defendiendo los de- 
rechos humanos, la posibilidad de conjugar individualismo y cosmopolitismo, así como la aspiración a lo mejor junto a la fundada desconfianza en que la búsqueda resultará inacabable, como el título de uno de sus más famosos opúsculos ya daba a entender, al decir no La paz perpetua, sino Zum ewigen Frieden, Hacia la paz perpetua, sin querer referirse con ella, naturalmente, a la de los cementerios. Y sin excluir, a pesar de todos los pesares, pero teniendo en cuenta también la belleza y la grandeza moral, la posibilidad de un último sentido, no racionalmente demostrable, pero en el que tal vez se pueda razonablemente confiar, pues, como el propio Kolakowski pregunta al final de su Horror metaphysicus: "¿No es plausible la sospecha de que si "el ser" y el universo carecieran de sentido, nunca hubiésemos alcanzado no ya la capacidad de imaginar lo contrario ni siquiera la capacidad de pensar precisamente eso: que "el ser" y el universo carecen de sentido?».

Sea de ello lo que fuere, quien busque cumplida información (en realidad, una erudición portentosa), claridad expositiva que no ahorra engañosamente los pasajes más arduos pero tampoco los complica de modo artificial y pretencioso («quien se expresa oscuramente tiene pensamientos enmarañados»), argumentación rigurosa y un pensamiento nutrido de los clásicos (¿fue por ello por lo que en cierta ocasión observó que «un filósofo moderno que jamás haya experimentado el sentimiento de ser un charlatán dará muestra de tener una mentalidad tan roma que, probablemente, su obra no sea digna de lectura»?), pero que también se encuentra al tanto de muchos de los principales debates de nuestro presente, quien busque eso y no sencillamente estar à la page o ejercer de «intelectual» (con frecuencia, los intelectuales son esos seres que quisieran preservar su sentimiento de superioridad, pero identificándose con una causa general, por lo que no paran de pensar y escribir sobre el sentido de su tarea, dado que no saben muy bien cuál es, pese a lo cual no cesan en tratar de convencernos de su importancia), quien busque todo eso, digo, encontrará en Leszek Kolakowski un excelente aliado, del que tendrá despúes - lo rechace, lo asuma o lo adopte en parteque des-liarse para tratar de ponerse en claro consigo mismo y nuestro mundo. No hay por qué desesperar. (Y quien no tenga tiempo o ganas, puede echar mano, sin necesidad de variar de autor y si la indolencia no le da para más, de su Gran Enciclopedia de la Filosofía y las ciencias sociales, de dos páginas, dedicada a todos aquellos que no quieren devanarse los sesos ni quemarse las pestañas).

Exiliado, crítico, independiente, con una inmensa sabiduría y un fino sentido del humor, Kolakowski no dejó de alentar el pensamiento y la responsabilidad moral del individuo, que él mismo practicó. En cierto sentido aislado, pero políglota y cosmopolita, su independencia se refleja bien en la anécdota narrada por Isaiah Berlin y recogida por Ernesto Krauze (Vuelta, 101, abril de 1985). Berlin le había preguntado acerca de su situación, a lo que Kolakowski le respondió: «Mire usted, Inglaterra es una isla en Europa, Oxford es una isla en Inglaterra, All Souls es una isla en Oxford y yo soy una isla en All Souls»». 